\title{
Petrol Fiyatları ile İşsizlik Oranı Arasındaki Saklı İlişkinin Analizi: Türkiye Örneği
}

(Araştırma Makalesi)

\author{
Analyzing the Hidden Relationship between Oil Prices and Unemployment \\ Rate: The Case of Turkey
}

Doi: 10.29023/alanyaakademik.676768

\section{Mustafa Orhan ÖZER}

Dr.

mustafaorhanozer@gmail.com

Orcid No: 0000-0002-3222-9913

How to cite this article: Özer M. O. (2020). "Petrol Fiyatları ile İssizlik Oranı Arasındaki Saklı İlişkinin Analizi: Türkiye Örneği”, Alanya Akademik Bakış, 4(3), Sayfa No. 875-887.

Anahtar kelimeler:
Petrol Fiyatları,
İssizlik Oranı,
Fourier Yaklaşımı,
Saklı Eşbütünleşme
Testi
Makale Geliş Tarihi:
17.01.2020
Kabul Tarihi:
O2.09.2020

Keywords:
Oil Prices,
Unemployment Rate,
Fourier Approach,
Hidden
Cointegration Test

ÖZET

Bu çalışmada, Türkiye'de 2005:01-2019:08 dönemi için petrol fiyatlart ile işsizlik oranı arasındaki uzun dönemli ilişki Fourier yaklaşımı çerçevesinde analiz edilmiştir. Fourier ADL eşbütünleşme testine göre değişkenler arasında uzun dönemli ilişki bulunmamakta, Fourier ADL saklı eşbütünleşme testine göre ise değişkenlerin negatif bileşenleri arasinda uzun dönemli ilişki bulunmaktadır. Uzun dönem katsayıları FMOLS yöntemi ile tahmin edilmiştir. Analiz sonucunda literatürde yer alan çoğu çalışmanın aksine, Türkiye'de petrol fiyatlarının işsizlik oranını ters yönde etkilediğ tespit edilmiştir.

\begin{abstract}
In this study, the long-term relationship between oil prices and unemployment rate in Turkey for the period 2005:01-2019:08 is analysed with Fourier approach. According to the Fourier ADL cointegration test, there is no long-term relationship between the variables while according to the hidden Fourier ADL cointegration test, there is a long-term relationship between the negative components of variables. Long-term coefficients are estimated by the FMOLS method. The analysis show that unlike most of the articles in the literature there is a negative impact of oil prices on unemployment rate in Turkey.
\end{abstract}

\section{GİRIŞ}

Günümüzün üretim sisteminde oldukça kritik bir konumda olan petrol, bütün ekonomiler için en önemli enerji kaynakları arasında yer almaktadır. Artan nüfusun ihtiyaçlarını karşılamak için reel çıktı düzeyinin yükselmesi, gelişmekte olan ülkelerin sanayileşmesi gibi faktörler enerji kaynaklarına olan ihtiyacın sürekli artmasına neden olmaktadır. Güneş enerjisi, rüzgar 
enerjisi, hidrolik enerji gibi yenilenebilir enerji kaynakları ile nükleer enerji gibi yenilenemez enerji kaynaklarının giderek daha fazla önem kazanmasına rağmen, petrolün önümüzdeki yıllarda da bu kritik konumunu koruyacağını tahmin etmek zor değildir. Ne var ki, diğer yeraltı ve yerüstü kaynaklarda olduğu gibi petrol de dünya üzerinde eşit bir dağılım göstermemektedir. Bu durum, ülkelerin petrol ihraç eden ve petrol ithal eden ülkeler şeklinde sınıflandırılmasına yol açmaktadır. Türkiye coğrafi olarak bu enerji kaynağından mahrum olduğu için ikinci grup ülkeler arasında yer almaktadır.

Petrol fiyatlarında meydana gelen değişimler reel ekonomik aktiviteyi çeşitli kanallardan etkilemektedir. Klasik arz yanlı etkiye göre; yükselen petrol fiyatları, üretim faaliyetleri için temel girdi niteliğinde olan enerji faktöründe kıtlık sorununun arttığına işaret etmektedir. Böylece çıktı büyüme oranı ve verimlilik azalırken işsizlik oranı artmaktadır (Brown ve Yücel, 2002). Transfer etkisine göre; petrol fiyatlarının yükselmesi, servetin petrol ithal eden ülkelerden petrol ihraç eden ülkelere kaymasına neden olmaktadır (Lardic ve Mignon, 2008: 848). Klasik yaklaşımın aksine, bu yaklaşımın aktarım mekanizması talep cephesi üzerinden işlemektedir (Nusair, 2020). Petrol fiyatlarının artması, petrol ithal eden ülkelerde toplam talebin ve dolayısıyla ekonomik büyümenin azalmasına; petrol ihraç eden ülkelerde ise artmasına yol açmaktadır. Böyle bir durumda, işsizlik oranı petrol ithal eden ülkelerde artarken, petrol ihraç eden ülkelerde azalmaktadır (Sköld, 2020: 8). Petrol fiyatlarının düşmesi durumunda ise bu süreç ters yönde işlemekte ve petrol ithal eden ülkelerde refah seviyesinin yükselmesiyle sonuçlanmaktadır. Reel balans etkisine göre; yükselen petrol fiyatları para talebinin artmasına yol açmaktadır. Merkez bankası tarafından kontrol edilen para arzının para talebinde meydana gelen artı̧ kadar genişletilmemesi durumunda, faiz oranı yükselmekte ve ekonomik büyüme oranı azalmaktadır (Doğrul ve Soytaş, 2010: 1524). Para piyasalarının dengede olması halinde ise bu etkiler ortaya çıkmamaktadır. Belirsizlik etkisine göre; petrol fiyatlarındaki belirsizlikler güven ortamının azalmasına, yatırımların ertelenmesine ve ekonomik büyümenin azalmasına yol açmaktadır (Öksüzler ve İpek, 2011: 18).

Petrol fiyatlarındaki değişimin ekonomik büyüme, enflasyon ve işsizlik oranları gibi çeşitli makroekonomik göstergeler üzerinde etkili olduğu bilinmektedir. Ancak petrol fiyatlarının bu göstergeler içerisinde, işsizlik oranı üzerindeki etkilerinin daha kararlı olduğu ifade edilebilir. Vasconez (2015) petrol fiyatları ve işsizlik oranı arasındaki ilişkiyi yeni Keynesyen yaklaşım çerçevesinde ele aldığ çalışmasında bu hipotezi destekleyen iddialarda bulunmuştur. 1970'li yıllarda petrol fiyatlarında meydana gelen yükselişler ABD ekonomisinin daralmasına neden olmuştur. Fakat petrol fiyatlarının 2002-2008 yılları arasındaki yükselişi büyüme ve enflasyon oranından ziyade işsizlik oranı üzerinde şiddetli bir etki yaratmıştır. Diğer taraftan, Kocaaslan (2019) petrol fiyatlarındaki belirsizliklerin işsizlik oranının artmasına neden olduğunu ifade etmektedir. Üretim maliyetleri etkisine göre; petrol fiyatlarındaki yükselme, özellikle bu enerji kaynağının yoğun bir biçimde kullanıldığı sektörlerde işsizlik oranının yükselmesine yol açmaktadır (Loungani, 1986). Enflasyon etkisine göre ise petrol fiyatlarının artması üretim maliyetlerinin, enflasyon oranının, faiz oranının yükselmesine, yatırım ve üretimin azalmasına neden olmaktadır (Tang vd., 2010).

Wijnbergen (1985), 1973 Petrol krizinin işsizlik oranı üzerindeki etkilerinin gelişmiş ve gelişmekte olan ülkeler için farklılık gösterdiğini belirtmektedir. Ahmad (2013: 50) ise petrol fiyatlarında meydana gelen değişimlerin işsizlik oranı üzerindeki etkilerinin farklı dönemler için de çeşitlilik gösterebileceğine işaret etmektedir. Ancak genel olarak petrol fiyatlarındaki 
artışların ekonomi üzerindeki etkilerinin petrol ihraç eden ülkeler için olumlu, petrol ithal eden ülkeler için ise olumsuz olacağı kabul edilmektedir. Türkiye'nin petrol ithal eden bir ülke olduğu göz önünde bulundurulduğunda, petrol fiyatlarındaki artışların işsizlik oranını arttırması beklenmektedir.

$\mathrm{Bu}$ çalışmanın temel amacı, Türkiye'de petrol fiyatları ile işsizlik oranı arasındaki uzun dönemli ilişkinin varlığını araştırmaktır. Çalışmanın bundan sonraki bölümlerinde sırasıyla konuya ilişkin literatüre yer verilecek, kullanılan yöntem hakkında bilgi verilecek, ampirik bulgular değerlendirilecek ve çalışma sonuç bölümüyle sonlandırılacaktır.

\section{LITERATÜR TARAMASI}

Literatürde çeşitli ülkeler için petrol fiyatları ile işsizlik oranı arasındaki ilişkiyi araştıran çalışmalara bakıldığında, büyük bir kısmında değişkenler arasında uzun dönemli ilişki bulunduğu görülmektedir. Gil-Alana (2003) Avustralya için 1971:Q1-1995:Q2 dönemine ait üç aylık verileri kullanarak Robinson yaklaşımı çerçevesinde, Ahmad (2013) Pakistan için 1991:01-2010:12 dönemine ait aylık verileri kullanarak Toda-Yamamoto nedensellik testi ile petrol fiyatları ve işsizlik oranı arasındaki ilişkiyi ele almışlardır. Elde edilen bulgular değişkenler arasında uzun dönemli ilişki olduğunu ortaya koymaktadır.

Gunu ve Kilishi (2010) tarafından yapılan çalışmada Nijerya'da 1990-200 dönemi VAR analizi ile, Karlsson vd. (2018) tarafından yapılan çalışmada ise Norveç’te 1997:01-2015:12 dönemi Granger ve Toda-Yamamoto nedensellik testleri ile irdelenmiştir. Petrol ihraç eden her iki ülkede de, petrol fiyatlarında meydana gelen artışın işsizlik oranının azalmasına yol açtığ 1 tespit edilmiştir.

Lescaroux ve Mignon (2008) çalışmalarında, 21 petrol ihraç eden, 15 petrol ithal eden ülkede 1960-2005 dönemini Pedroni panel eşbütünleşme ve Granger nedensellik testleri ile incelemişlerdir. Analiz sonucunda, özellikle OPEC üyesi olmayan ülkelerde petrol fiyatlarındaki artışın işsizlik oranının yükselmesine neden olduğu sonucuna ulaşılmıştır. Senzangakhona ve Choga (2015) tarafindan yapılan çalışmada Güney Afrika'da 1990-2010 dönemi Johansen eşbütünleşme testi ile analiz edilmiştir. Ulaşılan sonuçlara göre, petrol fiyatlarında meydana gelen artış işsizlik oranının kısa dönemde azalmasına, uzun dönemde ise artmasına sebep olmaktadır.

Rahma vd. (2016) tarafından yapılan çalışmada, Sudan'da 2000-2014 dönemi VAR analizi ve Granger nedensellik testi aracılığıyla değerlendirmeye alınmıştır. Çalışmada, 1999 yılından itibaren Petrol ihraç eden bir ülke olmasına rağmen, petrol fiyatlarında meydana gelen düşüşün Sudan'da işsizlik oranının azalmasına yol açtığı tespit edilmiştir. Bu durumun ortaya çıkmasında söz konusu dönemde hükümet tarafından uygulanan istihdam politikalarının, diğer ülkelere yapılan göçlerin ve 2011 yılında Güney Sudan'ın ayrılmasının etkili olabileceği belirtilmektedir.

Cuestas ve Gil-Alana (2016) Orta ve Doğu Avrupa ülkelerinde 2000:Q1-2015:Q4 dönemini ARDL sınır testi yaklaşımını kullanarak, Karaki (2018) ABD’de 1976:01-2015:11 dönemini VAR analizi ve Granger nedensellik testi aracılığıyla araştırmışlardır. Bu çalışmalarda elde edilen bulgulara göre; petrol fiyatlarında meydana gelen pozitif şoklar işsizlik oranını azaltırken, negatif şoklar işsizlik oranını arttırmaktadır. Bocklet ve Baek (2017) ise Alaska'da 1987-2014 dönemini ARDL sınır testi yaklaşımı ile incelemiş ve işsizlik oranının petrol 
fiyatlarındaki pozitif şoklara daha fazla, negatif şoklara daha az tepki verdiğine dikkat çekmiştir.

Bouchaour ve Al-Zeaud (2012) tarafindan yapılan çalışmada Cezayir'de 1980-2011 dönemi Johansen-Juselius eşbütünleşme ve Granger nedensellik testleri yardımıyla, Cuestas (2016) tarafından yapılan çalışmada İspanya'da 1997:12-2016:04 dönemi ARDL sınır testi yaklaşımı kullanılarak analiz edilmiştir. Bu çalışmalarda petrol fiyatları ile işsizlik oranı arasında uzun dönemli ilişki olmadığ 1 sonucuna ulaşılmıştır. Trang vd. (2017) ise Vietnam'da 2000-2015 dönemini VAR analizi yaparak araştırmışlar ve petrol fiyatlarında meydana gelen değişimin işsizlik oranı üzerindeki etkisinin belirsiz olduğunu ifade etmişlerdir.

Literatürde Türkiye için petrol fiyatları ile işsizlik oranı arasındaki ilişkiyi inceleyen çalışmaların sayısı oldukça sınırlıdır. Mevcut çalışmaların ise büyük bir çoğunluğu petrol fiyatlarındaki artışın işsizlik oranını arttı̆̆ına işaret etmektedir. Doğrul ve Soytaş (2010) tarafindan yapılan ampirik çalışmada, Türkiye'de 2005:01-2009:08 dönemi için petrol fiyatları ile işsizlik oranı arasındaki ilişki Toda-Yamamoto nedensellik testi ile analiz edilmiş ve değişkenler arasında uzun dönemli ilişki olduğu sonucuna ulaşılmıştır. Erkan vd. (2011), Türkiye'de 2005:01-2009:12 dönemi için petrol fiyatları ile işsizlik oranı arasındaki ilişkiyi VAR analizi ve Granger nedensellik testlerini kullanarak araştırmışlardır. Analiz sonucunda değişkenler arasında uzun dönemli iliş̧ki olduğu ve petrol fiyatlarında meydana gelen artışın işsizlik oranını yükselttiği tespit edilmiştir. Mucuk ve Edirnegil (2017) VAR analizi ile 19802014 dönemini, Sinan (2018) ise Johansen eşbütünleşme ve Granger nedensellik testleri ile 1980-2016 dönemini değerlendirmeye almış ve benzer sonuçlara ulaşmışlardır. Diğer taraftan, Yardımcıoğlu ve Beşel (2013) tarafından yapılan çalışmada, Türkiye'de 1980-2012 dönemi için petrol fiyatları ile işsizlik oranı arasındaki ilişki Gregory-Hansen ve TodaYamamoto nedensellik testleri aracılığıyla incelenmiştir. Çalışmada değişkenler arasında uzun dönemli ilişki bulunmadığı ancak petrol fiyatlarından işsizlik oranına doğru tek yönlü nedensellik ilişkisi olduğu sonucuna ulaşılmıştır.

Türkiye üzerine yapılan bazı çalışmalarda, petrol fiyatlarındaki değişimin istihdam üzerindeki etkileri araştırılmıştır. Altay vd. (2013) tarafından yapılan çalışmada, 2000:01-2012:04 dönemi VAR analizi ve Granger nedensellik testi ile incelemeye alınmış ve petrol fiyatlarının istihdam üzerinde etkisi olmadığı bulgusuna ulaşılmışıı. Aldemir ve Kara (2014), 2005:01 2009:12 dönemini aynı yöntemler aracılığıyla analiz etmiş ve petrol fiyatlarının tarımsal istihdam üzerindeki etkisinin sınırlı, tarım dışı istihdam üzerindeki etkisinin ise yoğun olduğunu ifade etmişlerdir. Azazi ve Topkaya (2017) ise 1978-2014 dönemini Johansen eşbütünleşme testini kullanarak araştırmış ve petrol fiyatlarının imalat sanayi istihdam oranı üzerindeki etkisinin oldukça sınırlı olduğu sonucuna ulaşmışlardır.

\section{EKONOMETRIK YÖNTEM}

Bu çalışmada Türkiye'de petrol fiyatları ile işsizlik oranı arasındaki ilişki 2005:01-2019:08 dönemine ait aylık veriler kullanılarak analiz edilmiştir. Değişkenler arasındaki uzun dönemli iliş̧inin incelenmesi amacıyla Yılancı vd. (2019) tarafından geliştirilen Fourier ADL saklı eşbütünleşme testinden yararlanılmıştır. Bilindiği üzere Fourier yaklaşımına dayanan ekonometrik testler, yapısal kırılmaların sayısı, konumu ve formundan bağımsız olarak daima güçlü sonuçlar vermektedirler (Pascalau, 2010: 565). Saklı eşbütünleşme testleri ise bağımsız değişkenin pozitif ve negatif bileşenlerinin bağımlı değişkenin pozitif ve negatif bileşenleri üzerindeki etkilerinin tespit edilmesini sağlamaktadır (Narayan ve Gupta, 2015: 19). 
Dolayısıyla bu çalışmada kullanılan yöntemin her iki yaklaşımın avantajlarını da taşıdığını söylemek mümkündür.

\subsection{Fourier ADF Birim Kök Testi}

Christopoulos ve Leon-Ledesma (2010) tarafindan geliştirilen Fourier ADF birim kök testi uygulanırken (1) numaralı denklem dikkate alınmaktadır:

$y_{t}=\delta_{0}+\delta_{1} \sin \left(\frac{2 \pi k t}{T}\right)+\delta_{2} \cos \left(\frac{2 \pi k t}{T}\right)+v_{t}, \quad \pi=3.1415$

Burada $\mathrm{k}$ frekans değerini, $\mathrm{t}$ trendi ve $\mathrm{T}$ örneklem büyüklügüün göstermektedir. Fourier ADF birim kök testinin uygulanmasında üç aşamalı bir yöntem takip edilmektedir. İlk aşamada en uygun frekans değeri $\left(\mathrm{k}^{*}\right)$ tespit edilmektedir. 6'dan küçük pozitif tam sayılar arasından kalıntı kareler toplamını (KKT) minimize eden değer, en uygun frekans değeri olarak tanımlanmaktadır (Christopoulos ve Leon-Ledesma, 2010: 1080). Uygun frekans değerinin belirlenmesinden sonra kalıntılar elde edilmektedir:

$\hat{v}_{t}=y_{t}-\hat{\delta}_{0}+\hat{\delta}_{1} \sin \left(\frac{2 \pi k^{*} t}{T}\right)+\delta_{2} \cos \left(\frac{2 \pi k^{*} t}{T}\right)$

İkinci aşamada kalıntılara birim kök testi uygulanmaktadır.

$\Delta v_{t}=\alpha_{1} v_{t-1}+\sum_{j=1}^{p} \beta_{j} \Delta v_{t-j}+u_{t}$

Burada $u_{t}$ beyaz gürültülü hata terimini, $p$ hata terimindeki otokorelasyonu ortadan kaldırmak için ihtiyaç duyulan maksimum değeri göstermektedir. Fourier ADF birim kök testi, (3) numaralı denklemin kalıntılara uygulanması ile gerçekleştirilmektedir. Değişkenin durağan olmadığını ifade eden temel hipotez (4) numaralı denklemde, durağan olduğunu ifade eden alternatif hipotez ise (5) numaralı denklemde görülmektedir (Yılancı ve Eriş, 2013: 24). Test için gerekli olan kritik değerler Christopoulos ve Leon-Ledesma (2010) tarafindan belirlenmiştir.

$H_{0}: \alpha_{1}=0$

$H_{1}: \alpha_{1}<0$

Son aşamada, trigonometrik terimlerin anlamlılıkları $\mathrm{F}$ testi aracılığıyla sınanmaktadır. Trigonometrik terimlerin anlamsız olduğunu ifade eden temel hipotez (6) numaralı denklemde, anlamlı olduğunu ifade eden alternatif hipotez ise (7) numaralı denklemde görülmektedir (Yılancı ve Eriş, 2013: 24):

$H_{0}: \delta_{1}=\delta_{2}=0$

$H_{1}: \delta_{1}=0$ ve/veya $\delta_{2} \neq 0$

F testi için gerekli olan kritik değerler Becker vd. (2006) tarafından belirlenmiştir.

\subsection{Fourier ADL Eşbütünleşme Testi}

Banerjee vd. (2017) tarafından önerilen Fourier ADL eşbütünleşme testi, Banerjee vd. (1998) tarafından geliştirilen ADL eşbütünleşme testinin Fourier fonksiyonları ile genişletilmesiyle elde edilmiştir. Petrol fiyatları ve işsizlik oranı arasındaki uzun dönemli ilişkinin, Fourier ADL eşbütünleşme testi ile incelenmesi için (8) numaralı denklem dikkate alınmaktadır: 
$\Delta U N_{t}=\alpha_{0}+\alpha_{1} \sin \left(\frac{2 \pi k^{*} t}{T}\right)+\alpha_{2} \cos \left(\frac{2 \pi k^{*} t}{T}\right)+\alpha_{3} U N_{t-1}+\alpha_{4} O P_{t-1}+\alpha_{5} \Delta U N_{t-1}+$ $\alpha_{6} \Delta O P_{t-1}+e_{t}$

Burada UN işsizlik oranını, OP petrol fiyatlarını, $e_{t}$ hata terimini göstermektedir. Hata teriminde ortaya çıkması muhtemel olan otokorelasyonun kontrol altına alınması için fark değişkenlerinin gecikmeli değerleri modele dahil edilmektedir (Banerjee vd., 2017: 117). $k^{*}$ değerinin belirlenmesinde Akaike bilgi kriteri dikkate alınmaktadır (Lee vd., 2019: 637). Değişkenler arasında uzun dönemli ilişki olmadığını ifade eden temel hipotez (9) numaralı denklemde, uzun dönemli ilişki olduğunu ifade eden alternatif hipotez ise (10) numaralı denklemde görülmektedir:

$H_{0}: \alpha_{3}=0$

$H_{1}: \alpha_{3}<0$

Test istatistiğinin hesaplanmasında (11) numaralı denklem dikkate alınmaktadır:

$t_{A D L}^{F}=\frac{\widehat{\alpha}_{3}}{s e\left(\widehat{\alpha}_{3}\right)}$

Burada $\hat{\alpha}_{3}, \alpha_{3}$ 'ün sıradan en küçük kareler tahmincisini ve $\operatorname{se}\left(\widehat{\alpha}_{3}\right), \hat{\alpha}_{3}$ 'ün standart hatasını göstermektedir. Test için gerekli olan kritik değerler Banerjee vd. (2017) tarafından belirlenmiştir.

\subsection{Fourier ADL Saklı Eşbütünleşme Testi}

Granger ve Yoon (2002) çalışmalarında, Engle ve Granger (1987) tarafından önerilen eşbütünleşme testini; Hatemi-J ve Irandoust (2012) ise çalışmalarında, Johansen (1988) tarafından önerilen eşbütünleşme testini geliştirerek, değişkenlerin pozitif ve negatif şokları arasındaki uzun dönemli ilişkiyi dikkate alan eşbütünleşme testlerini önermişlerdir. Yılancı vd. (2019) tarafından önerilen Fourier ADL saklı eşbütünleşme testi de Fourier ADL eşbütünleşme testinin benzer yöntemle geliştirilmesiyle elde edilmiştir. İlk olarak, (12) ve (13) numaralı denklemlerde görüldüğü gibi değişkenlerin kümülatif pozitif ve negatif şokları elde edilmektedir:

$U N_{t}=U N_{t-1}+e_{t}=U N_{0}+\sum_{i=1}^{t} e_{i}^{+}+\sum_{i=1}^{t} e_{i}^{-}$
$O P_{t}=O P_{t-1}+\varepsilon_{t}=O P_{0}+\sum_{i=1}^{t} \varepsilon_{i}^{+}+\sum_{i=1}^{t} \varepsilon_{i}^{-}$

Burada $U N_{0}$ ve $O P_{0}$, ilgili değişkenlerin başlangıç değerlerini $e_{i}^{+}, e_{i}^{-}, \varepsilon_{i}^{+}$ve $\varepsilon_{i}^{-}$ise pozitif ve negatif şokları göstermektedir. (14) numaralı denklemde görüldüğü üzere, pozitif ve negatif şokların kümülatif formda ifade edilmesi mümkündür (Y1lancı vd., 2019: 4):

$U N_{t}^{+}=\sum_{i=1}^{t} e_{i}^{+}, U N_{t}^{-}=\sum_{i=1}^{t} e_{i}^{-}, O P_{t}^{+}=\sum_{i=1}^{t} \varepsilon_{i}^{+}, O P_{t}^{-}=\sum_{i=1}^{t} \varepsilon_{i}^{-}$

(15) numaralı denklem pozitif bileşenler arasındaki, (16) numaralı denklem ise negatif bileşenler arasındaki uzun dönemli ilişkinin varlığını sınamak amacıyla kullanılmaktadır:

$\Delta U N_{t}^{+}=\alpha_{0}+\alpha_{1} \sin \left(\frac{2 \pi k^{*} t}{T}\right)+\alpha_{2} \cos \left(\frac{2 \pi k^{*} t}{T}\right)+\alpha_{3} U N_{t-1}^{+}+\alpha_{4} O P_{t-1}^{+}+\alpha_{5} \Delta U N_{t-1}^{+}+$
$\alpha_{6} \Delta O P_{t-1}^{+}+\varsigma_{t}$ 


$$
\begin{aligned}
& \Delta U N_{t}^{-}=\alpha_{0}+\alpha_{1} \sin \left(\frac{2 \pi k^{*} t}{T}\right)+\alpha_{2} \cos \left(\frac{2 \pi k^{*} t}{T}\right)+\alpha_{3} U N_{t-1}^{-}+\alpha_{4} O P_{t-1}^{-}+\alpha_{5} \Delta U N_{t-1}^{-}+ \\
& \alpha_{6} \Delta O P_{t-1}^{-}+\xi_{t}
\end{aligned}
$$

Fourier ADL saklı eşbütünleşme testinin sonraki aşamaları, Fourier ADL eşbütünleşme testindeki gibi olmaktadır (Yılancı vd., 2017: 4). Pozitif veya negatif bileşenler arasında uzun dönemli ilişki bulunması halinde, değişkenler arasında saklı ilişki olduğu kabul edilmektedir.

\section{VERİ VE AMPİIIK BULGULAR}

Bu çalışmada, Türkiye'de petrol fiyatlarının işsizlik oranı üzerindeki etkileri incelenmektedir. Petrol fiyatları göstergesi olarak kullanılan Avrupa Brent Petrol Spot fiyatı (varil başına dolar cinsinden), TCMB elektronik veri dağıtım sisteminden; işsizlik oranı göstergesi olarak kullanılan harmonize edilmiş toplam işsizlik oranı ise Federal Reserve Bank of St. Louis (FRED) veri dağıtım sisteminden elde edilmiştir. Daha geniş bir dönemi kapsamalarına rağmen gözlem sayılarının düşük olması nedeniyle üç aylık ve yıllık zaman serileri yerine aylık seriler tercih edilmiştir. Çalışmada kullanılan veriler mevsimsel etkilerden arındırılmış olup 2005:01-2019:08 dönemini kapsamaktadır.

İşsizlik oranı (UN) ve petrol fiyatları (OP) değişkenlerinin durağanlık durumlarını analiz etmek amaciyla uygulanan Fourier ADF birim kök testine ait sonuçlar Tablo 1'de sunulmuştur.

Tablo 1. Fourier ADF Birim Kök Testine Ait Sonuçlar

\begin{tabular}{|c|c|c|c|c|}
\hline Değişkenler & $\mathbf{k}^{*}$ & Min KKT & FADF & F istatistiğ \\
\hline UN & 2 & 270.3474 & -2.12 & 43.61842 \\
\hline OP & 1 & 39932.90 & -3.83 & 114.3165 \\
\hline FARKUN & 3 & 9.586229 & -4.48 & 10.25638 \\
\hline FARKOP & 5 & 714.1575 & -3.32 & 17.47146 \\
\hline
\end{tabular}

Not: Uygun gecikme sayılarının belirlenmesinde Schwarz bilgi kriteri dikkate alınmıştır. FADF testinde $\% 1, \% 5, \% 10$ anlamlılık seviyelerinde kritik değerler sirasıyla $\mathrm{k}=1$ için $-4.43,-3.85,-3.52, \mathrm{k}=2$ için $3.95,-3.28,-2.91, \mathrm{k}=3$ için $-3.70,-3.06,-2.71$ ve $\mathrm{k}=5$ için $-3.55,-2.80,-2.56$ şeklindedir. $\mathrm{F}$ testinde $\% 1$, $\% 5, \% 10$ anlamlılık seviyelerinde kritik değerler sirasıyla 4.133, 4.929, 6.730 olarak belirlenmiştir.

Tablo 1'de görüldüğü üzere, değişkenlere ilk olarak düzeyde Fourier ADF birim kök testi uygulanmıştır. Hesaplanan istatistik değerlerinin \%5 anlamlılık seviyesi için belirlenen kritik değerlerden küçük olduğu ve değişkenlerin düzeyde durağan olmadıkları görülmüştür. Bunun üzerine serilerin birinci farkı alındıktan sonra yeniden Fourier ADF birim kök testi uygulanmıştır. Hesaplanan istatistik değerlerinin \%5 anlamlılık seviyesi için belirlenen kritik değerlerden büyük oldukları ve fark değişkenlerin durağan oldukları tespit edilmiştir. Bütün değişkenler için hesaplanan $\mathrm{F}$ istatistik değerlerinin, kritik değerlerden büyük olduğu ve trigonometrik terimlerinin anlamlı olduğu görülmüştür. UN ve OP değişkenlerinin I(1) olduğu tespit edildikten sonra, değişkenler arasındaki uzun dönemli ilişkinin varlığını incelemek için Fourier ADL eşbütünleşme testi uygulanmıştır. Test sonuçlar Tablo 2'de yer almaktadir.

Tablo 2. Fourier ADL Eşbütünleşme Testine Ait Sonuçlar

\begin{tabular}{|c|c|c|c|c|c|c|}
\hline $\begin{array}{c}\text { Bağımlı } \\
\text { Değişsen }\end{array}$ & $\begin{array}{c}\text { Bağımsız } \\
\text { Değişken }\end{array}$ & $\mathbf{k}^{*}$ & $\begin{array}{c}\text { Bağımlı } \\
\text { Değişkenin } \\
\text { Gecikmesi }\end{array}$ & $\begin{array}{c}\text { Bağımsız } \\
\text { Değişkenin } \\
\text { Gecikmesi }\end{array}$ & Min AIC & $\begin{array}{c}\text { FADL } \\
\text { Eşbütünleşme } \\
\text { Test İstatistiği }\end{array}$ \\
\hline UN & OP & 1 & 3 & 1 & -0.184234 & -0.270268 \\
\hline
\end{tabular}


Not: \%1, \%5, \%10 anlamlılık seviyelerinde kritik değerler sırasıyla k=1 için $-4.73,-4.09,-3.76$ şeklindedir.

Tablo 2'ye bakıldığında, test istatistiğinin bütün anlamlılık seviyeleri için kritik değerden küçük olduğu görülmektedir. Dolayısıyla Fourier ADL eşbütünleşme testine göre UN ve OP değişkenleri arasında uzun dönemli bir ilişki bulunmamaktadır.

UN ve OP arasındaki saklı ilişkinin araştırılması için değişkenler pozitif ve negatif bileşenlerine ayrılmıştır. Öncelikle, bu bileşenlerin durağanlık durumlarını analiz etmek için Fourier ADF birim kök testi uygulanmıştır. Test sonuçlar Tablo 3 'te görüldüğü gibidir.

Tablo 3. Negatif ve Pozitif Bileşenler için Uygulanan Fourier ADF Birim Kök Testine Ait Sonuçlar

\begin{tabular}{|c|c|c|c|c|}
\hline Değişkenler & $\mathbf{k}^{*}$ & Min KKT & FADF & F istatistiği \\
\hline UNN & 1 & 1307.691 & -0.65 & 164.2250 \\
\hline OPN & 1 & 161020.0 & -0.97 & 132.0482 \\
\hline UNP & 1 & 2408.781 & -0.22 & 94.56870 \\
\hline OPP & 1 & 160403.9 & -1.02 & 137.1436 \\
\hline FARKUNN & 2 & 2.329140 & -6.49 & 5.857230 \\
\hline FARKOPN & 2 & 285.8260 & -3.82 & 24.77704 \\
\hline FARKUNP & 3 & 4.488678 & -6.03 & 11.27459 \\
\hline FARKOPP & 1 & 200.0241 & -4.09 & 17.53981 \\
\hline
\end{tabular}

Not: Uygun gecikme sayılarının belirlenmesinde Schwarz bilgi kriteri dikkate alınmıştır. FADF testinde $\% 1, \% 5, \% 10$ anlamlılık seviyelerinde kritik değerler sırasıyla $\mathrm{k}=1$ için $-4.43,-3.85,-3.52, \mathrm{k}=2$ için $3.95,-3.28,-2.91$ ve $\mathrm{k}=3$ için $-3.70,-3.06,-2.71$ şeklindedir. $\mathrm{F}$ testinde $\% 1, \% 5, \% 10$ anlamlılık seviyelerinde kritik değerler sırasıyla 4.133, 4.929, 6.730 olarak belirlenmiştir.

Tablo 3’te görüldüğü üzere, UN ve OP değişkenlerinin pozitif ve negatif bileşenlerine ilk olarak düzeyde Fourier ADF birim kök testi uygulanmıştır. Elde edilen test istatistiklerinin bütün anlamlılık seviyelerinde kritik değerlerden küçük çıktığı ve bileşenlerin düzeyde birim köklü olduğu anlaşılmıştır. Bunun üzerine, söz konusu bileşenlerin birinci farkı alındıktan sonra tekrar Fourier ADF birim kök testi uygulanmıştır. Farkı alınan bileşenler için hesaplanan test istatistiklerinin $\% 5$ anlamlılık seviyesinde kritik değerlerden yüksek olduğu görülmektedir. Ayrıca hesaplanan $\mathrm{F}$ istatistik değerlerinin de $\% 5$ anlamlllık seviyesinde kritik değerden büyük olduğu görülmüş ve trigonometrik terimlerinin anlamlı olduğu anlaşılmıştır. İncelenen bütün bileşenlerin I(1) olduğu tespit edildikten sonra, değişkenler arasındaki saklı ilişkinin varlığını araştırmak için Fourier ADL saklı eşbütünleşme testi uygulanmıştır. Test sonuçları Tablo 4'te yer almaktadır.

Tablo 4. Fourier ADL Saklı Eşbütünleşme Testine Ait Sonuçlar

\begin{tabular}{|c|c|c|c|c|c|c|}
\hline $\begin{array}{c}\text { Bağımlı } \\
\text { Değişken }\end{array}$ & $\begin{array}{c}\text { Bağımsız } \\
\text { Değişken }\end{array}$ & $\mathbf{k}^{*}$ & $\begin{array}{c}\text { Bağımlı } \\
\text { Değişkenin } \\
\text { Gecikmesi }\end{array}$ & $\begin{array}{c}\text { Bağımsız } \\
\text { Değişkenin } \\
\text { Gecikmesi }\end{array}$ & Min AIC & $\begin{array}{c}\text { FADF Saklı } \\
\text { Eşbütünleşme } \\
\text { Test İstatistiği }\end{array}$ \\
\hline UNN & OPN & 1 & 3 & 1 & -1.591530 & -4.259913 \\
\hline UNP & OPP & 1 & 2 & 1 & -0.904985 & -2.971833 \\
\hline
\end{tabular}

Not: $\% 1, \% 5, \% 10$ anlamlılık seviyelerinde kritik değerler sırasıyla $\mathrm{k}=1$ için $-4.73,-4.09,-3.76$ şeklindedir.

Tablo 4 incelendiğinde, pozitif bileşenler için hesaplanan test istatistiğinin kritik değerlerden küçük olduğu görülmektedir. Diğer taraftan, negatif bileşenler için hesaplanan test istatistiği 
\%5anlamlılık seviyesinde kritik değerden büyük çıkmıştır. Bu durum, değişkenler arasında saklı eşbütünleşme ilişkisi olduğuna işaret etmektedir. Uzun dönemli katsayıları tahmin etmek için Tam Modifiye Edilmiş En Küçük Kareler (FMOLS) yöntemi kullanılmıştır. Test sonuçlar Tablo 5 'te görüldüğü gibidir.

Tablo 5. Uzun Dönem Katsayılarının Tahmini

\begin{tabular}{|c|c|c|c|c|c|}
\hline $\begin{array}{c}\text { Bağımlı } \\
\text { Değişken }\end{array}$ & $\begin{array}{c}\text { Bağımsız } \\
\text { Değișken }\end{array}$ & Katsayı & $\begin{array}{c}\text { Standart } \\
\text { Hata }\end{array}$ & t istatistiği & Olasılık \\
\hline \multirow{2}{*}{ UNN } & Sabit Terim & -1.665 & 0.824 & -2.018 & 0.045 \\
\cline { 2 - 6 } & OPN & 0.099 & 0.010 & 9.421 & 0.000 \\
\hline
\end{tabular}

Not: Uygun gecikme sayısının belirlenmesinde Akaike bilgi kriteri kullanılmıştır.

Tablo 5'te FMOLS yöntemi kullanılarak tahmin edilen uzun dönem katsayıları yer almaktadır. Her iki katsayının da anlamlı olduğu görülmektedir. Buna göre OP'nin negatif bileşenlerinde meydana gelen yüzde 1'lik artış, UN'nin negatif bileşenlerinde yaklaşık yüzde 0.10'luk bir artışa neden olmaktadır. Negatif bileşenler arasında pozitif ilişki olması, değişkenler arasında ters yönlü ilişki olduğu anlamına gelmektedir (Yılancı vd., 2019: 4). Dolayısıyla Türkiye'de uzun dönemde petrol fiyatlarındaki değişim işsizlik oranını ters yönde etkilemektedir.

\section{SONUC}

Bu çalışmada 2005:01-2019:08 dönemi için Türkiye'de petrol fiyatları ile işsizlik oranı arasındaki ilişki Fourier yaklaşımı çerçevesinde incelenmiştir. İlk olarak, değişkenlerin durağanlıkları Fourier ADF birim kök testi ile incelenmiş ve her iki değişkenin de düzeyde birim köklü, birinci farkı alındığında durağan hale geldiği tespit edilmiştir. Uygulanan Fourier ADL eşbütünleşme testine ait sonuçlar, değişkenler arasında uzun dönemli ilişki olmadığına işaret etmektedir. Bunun üzerine değişkenler negatif ve pozitif bileşenlerine ayrılmıştır. Fourier ADF birim kök testine göre bütün bileşenler düzeyde birim köklü, birinci fark1 alındığında durağan hale gelmektedir. Daha sonra değişkenler arasındaki ilişkiyi araştırmak için Fourier ADL saklı eşbütünleşme testi uygulanmıştır. Buna göre değişkenlerin pozitif bileşenleri arasında uzun dönemli ilişki bulunmazken, negatif bileşenleri arasında bulunmaktadır. Son olarak, FMOLS yöntemi kullanılarak uzun dönemli katsayılar tahmin edilmiş ve istatistiksel açıdan anlamlı bulunmuştur. Yapılan analizler petrol fiyatlarında meydana gelen değişimlerin işsizlik oranını ters yönde etkilediği ortaya koymaktadır.

Petrol ithal eden ülkeler arasında yer alan Türkiye'de, petrol fiyatlarındaki yükselişin teorik olarak işsizlik oranının da yükselmesine yol açması beklenmektedir. Buna rağmen, elde edilen bulgular değişkenlerin ters yönde hareket ettiklerini göstermektedir. Prasad vd. (2007) tarafından yapılan çalışmada, petrol ithalatına bağımlı bir ekonomik yapıya sahip olmasına rağmen, Fiji adasında petrol fiyatlarındaki yükselişlerin reel GSYİH'yi arttırdığı tespit edilmiştir. Fiji'de cari büyüme oranının potansiyel büyüme oranının altında olmasının bu sonucun ortaya çıkmasında etkili olduğu düşünülmekte ve cari büyüme oranının belirli bir eşik değeri aşmasından sonra değişkenlerin ters yönde hareket edeceği tahmin edilmektedir. Türkiye için de benzer bir durumun söz konusu olması oldukça muhtemel görünmektedir. Analiz edilen dönemde ortalama işsizlik oranının \%10'un üzerinde olduğu göz önünde bulundurulduğunda, Türkiye'de işsizlik oranının belirli bir seviyenin altına düşmesi, gelecek dönemlerde değişkenler arasındaki ilişkinin pozitif yönlü olmasına neden olabilir. 
Öksüzler ve İpek (2011) çalışmalarında, Türkiye'de ekonomik büyümenin petrol fiyatlarındaki yükselişlerden olumlu etkilendiğini tespit etmişlerdir. Şengönül vd. (2018) ise petrol fiyatlarında meydana gelen artışın ihracatı arttırdığını ifade etmişlerdir. Dolayısıyla ihracat ve ekonomik büyüme oranında görülen olumlu gelişmelerin işsizlik oranının azalmasında etkili olduğu düşünülebilir. Yaylalı ve Lebe (2012) çalışmalarında, petrol fiyatlarında meydana gelen artışların Türkiye'de enflasyonun en önemli nedenleri arasında olduğunu belirtmişlerdir. Bu durumda enflasyon oranının yükselmesi Phillips eğrisi gereğince işsizlik oranının azalmasına katkıda bulunmuş olabilir.

Ewing ve Thompson (2007) tarafından yapılan çalışmada, petrol fiyatlarındaki artışın istihdam oranının kısa vadede azalmasına, uzun vadede ise artmasına yol açtığı vurgulanmaktadır. Emek piyasasının farklı sektörleri arasında tamamlayıcılık ve ikame edilebilirlik özellikleri olması ve bu piyasanın tahmin edildiğinden daha hızlı tepki vermesinin bu sonucun ortaya çıkmasında etkili olduğu düşünülmektedir. Trang vd. (2017) tarafından da ifade edildiği gibi, petrol fiyatlarının yükselmesinin ekonomi üzerindeki olumsuz etkileri uzun dönemde ortadan kaldırılabilmektedir. Petrol maliyetlerinin artması işletmelerin enerjiyi verimli bir şekilde kullanmak için ileri teknolojilere yatırım yapmalarına neden olmakta ve bu alanda çeşitli politikaların üretilmesi için teşvik edici rol üstlenmektedir. Alternatif kaynaklara yönelik daha fazla politika geliştirilmesiyle petrol fiyatlarındaki artışın işsizlik üzerindeki olumsuz etkileri bertaraf edilmekte, hatta birtakım olumlu etkilerin ortaya çıkması söz konusu olmaktadır.

\section{KAYNAKÇA}

AHMAD, F. (2013). "The Effect of Oil Prices on Unemployment: Evidence from Pakistan", Business and Economics Research Journal, 4(1): 43-57.

ALDEMİR, Ş. \& KARA, M. (2014). “Türkiye'de İstihdam Dinamiklerine İlişskin Nedensellik Analizi”, TISK Akademi, 9(17): 24-38.

ALTAY, B., TOPCU, M., \& ERDOGAN, E. (2013). "Oil Price, Output and Employment in Turkey: Evidence from Vector Error Correction Model”, International Journal of Energy Economics and Policy, 3: 7-13.

AZAZI, H. \& TOPKAYA, Ö. (2017). "Petrol Fiyatlarındaki Değişikliğin Türkiye İmalat Sanayi Ve İstihdamı Üzerindeki Etkileri”, Selçuk Üniversitesi Sosyal Bilimler Meslek Yüksekokulu Dergisi, 20(1): 14-26.

BANERJEE, A., DOLADO, J., \& MESTRE, R. (1998). "Error-Correction Mechanism Tests for Cointegration in A Single-Equation Framework", Journal of Time Series Analysis, 19(3): 267-283.

BANERJEE, P., ARČABIĆ, V., \& LEE, H. (2017). "Fourier ADL Cointegration Test to Approximate Smooth Breaks with New Evidence from Crude Oil Market", Economic Modelling, 67(C): 114-124.

BECKER, R., ENDERS, W., \& LEE, J. (2006). “A Stationarity Test in the Presence of an Unknown Number of Smooth Breaks", Journal of Time Series Analysis, 27(3): 381 409. 
BOCKLET, J. \& BAEK, J. (2017). "Do Oil Price Changes have Symmetric or Asymmetric Effects on the Unemployment Rate?: Empirical Evidence from Alaska", Energy Sources, Part B: Economics, Planning, and Policy, 12(5): 402-407.

BOUCHAOUR, C. \& AL-ZEAUD, H. A. (2012). "Oil Price Distortion and Their Impact on Algerian Macroeconomic", International Journal of Business and Management, 7(18): 99-114.

BROWN, S. P. A \& YÜCEL, M. K. (2002). "Energy Prices and Aggregate Economic Activity: An Interpretative Survey", The Quarterly Review of Economics and Finance, 42(2): 193-208.

CHRISTOPOULOS, D. K. \& LEON-LEDESMA, M. A. (2010). "Smooth Breaks and Nonlinear Mean Reversion: Post-Bretton Woods Real Exchange Rates", Journal of International Money and Finance, 29(6): 1076-1093.

CUESTAS, J. C. (2016). "The Impact of Supply Shocks on Unemployment in Spain", Economics and Business Letters, 5(4): 107-112.

CUESTAS, J. C. \& GIL-ALANA, L. A. (2016). "Oil Shocks on Unemployment in Central and Eastern Europe", School of Economics and Business Administration, Faculty Working Papers, 2(16): 1-23.

DOĞRUL, H. G. \& SOYTAŞ, U. (2010). "Relationship between Oil Prices, Interest Rate, and Unemployment: Evidence from an Emerging Market", Energy Economics, 32(6): 1523-1528.

ENGLE, R. F. \& GRANGER, C. W. J. (1987). “Co-Integration and Error Correction: Representation, Estimation, and Testing”, Econometrica, 55(2): 251-276.

ERKAN, B., ŞENTÜRK, M., AKBAŞ, Y. E., \& BAYAT, T. (2011). "Uluslararası Ham Petrol Fiyatlarındaki Volatilitenin İşsizlik Göstergeleri Üzerindeki Etkisi: Türkiye Örneği Üzerine Ampirik Bulgular", 10(2): 715-730.

EWING, B. T. \& THOMPSON, M. A. (2007). "Dynamic Cyclical Comovements of Oil Prices with Industrial Production, Consumer Prices, Unemployment, and Stock Prices”, Energy Policy, 35(11): 5535-5540.

GIL-ALANA, L. A. (2003). "Unemployment and Real Oil Prices in Australia: A Fractionally Cointegrated Approach", Applied Economics Letters, 10(4): 201-204.

GRANGER, C. W. J. \& YOON, G. (2002). "Hidden Cointegration, University of California", Economics Working Paper, 1-48.

GUNU, U. \& KILISHI, A. A. (2010). "Oil Price Shocks and the Nigeria Economy: A Variance Autoregressive (VAR) Model", International Journal of Business and Management, 5(8): 39-49.

HATEMI-J, A. \& IRANDOUST, M. (2012). “Asymmetric Interaction between Government Spending and Terms of Trade Volatility: New Evidence from Hidden Cointegration Technique", Journal of Economic Studies, 39(3): 368-378. 
JOHANSEN, S. (1988). "Statistical Analysis of Cointegration Vectors", Journal of Economic Dynamics and Control, 12(2-3): 231-254.

KARAKI, M. B. (2018). "Oil Prices and State Unemployment Rates”, The Energy Journal, 39(3): 25-49.

KIM KARLSSON, H., LI, Y., \& SHUKUR, G. (2018). "The Causal Nexus between Oil Prices, Interest Rates, and Unemployment in Norway Using Wavelet Methods", Sustainability, 10(8): 1-15.

KOCAASLAN, Ö. K. (2019). “Oil Price Uncertainty and Unemployment”, Energy Economics, Energy Economics, 81: 577-583.

KOŞAROĞLU, Ş. M., ŞENGÖNÜL, A., \& KARADAŞ, H. A. (2018). "Petrol Fiyatlarının İhracat Üzerindeki Etkisi”, Yönetim ve Ekonomi, 25(2): 335-349.

LARDIC, S. \& MIGNON, V. (2008). "Oil Prices and Economic Activity: An Asymmetric Cointegration Approach", Energy Economics, 30(3): 847-855.

LEE, H., LEE, J., \& IM, K. (2019). "More Powerful Cointegration Tests with Non-Normal Errors", Studies in Nonlinear Dynamics and Econometrics, 19(4): 397-413.

LESCAROUX, F. \& MIGNON, V. (2008). "On the Influence of Oil Prices on Economic Activity and Other Macroeconomic and Financial Variables", OPEC Energy Review, 32(4): 343-38.

LOUNGANI, P. (1986). "Oil Price Shocks and the Dispersion Hypothesis", The Review of Economics and Statistics, 68(3): 363-539.

MUCUK, M. \& EDİRNEGİL, A. (2017). "Uluslararası Petrol Fiyatlarının İşsizlik Üzerine Etkisi: Türkiye Örneğii”, Uluslararası Politik, Ekonomik ve Sosyal Araştırmalar Kongresi Bildiri Özetleri Kitabı, 105.

NARAYAN, P. K. \& GUPTA, R. (2015). "Has Oil Price Predicted Stock Returns for Over a Century?”, Energy Economics, 48: 18-23.

NUSAIR, S. A. (2020). "The Asymmetric Effects of Oil Price Changes on Unemployment: Evidence from Canada and the U.S", The Journal of Economic Asymmetries, 21(C), $1-13$.

ÖKSÜZLER, O. \& İPEK, E. (2011). "Dünya Petrol Fiyatlarındaki Değişimin Büyüme ve Enflasyon Üzerindeki Etkisi: Türkiye Örneği”, ZKÜ Sosyal Bilimler Dergisi, 7(14): $15-34$.

PASCALAU, R. (2010). "Unit Root Tests with Smooth Breaks: An Application to the Nelson-Plosser Data Set", Applied Economics Letters, 17(6): 565-670.

PRASAD, A., NARAYAN, P. K., \& NARAYAN, J. (2007). "Exploring the Oil Price and Real GDP Nexus for a Small Island Economy, the Fiji Islands", Energy Policy, 35(12): 6506-6513.

RAHMA, E., PERERA, N., \& TAN, K. (2016). “Oil Price Shocks and Their Consequences on Sudan's GDP Growth and Unemployment Rates”, International Institute of Social 
and Economic Sciences, 21. International Academic Conference, 9-12 February 2016, Miami.

SENZANGAKHONA, P. \& CHOGA, I. (2015). "Crude Oil Prices and Unemployment in South Africa: 1990 - 2010”, Mediterranean Journal of Social Sciences, 6(2): 407414.

SKÖLD, E. (2020). “The Relationship Between Unemployment and Oil Price, Oil Price Uncertainty, and Interest Rates in Small Open Economies: A study on Sweden, Norway, Denmark, and Finland", (Master Thesis), Jönköping University International Business School, Jönköping.

SINAN, O. B. (2018). “Türkiye'de İşsizlik Oranları ile Uluslararası Petrol Fiyatları İlişkisi: 1980-2016”, Finans Ekonomi ve Sosyal Araştırmalar Dergisi, 3(4): 681-695.

TANG, W., WU, L., \& ZHANG, Z. (2010). “Oil Price Shocks and Their Short- and LongTerm Effects on The Chinese Economy”, Energy Economics, 32(1): 3-14.

TRANG, N. T. N., THO, T. N., \& HONG, D. T. T. (2017). "The Impact of Oil Price on the Growth, Inflation, Unemployment and Budget Deficit of Vietnam", International Journal of Energy Economics and Policy, 7(3): 42-49.

VASCONEZ, V. A. (2015). "Oil and Unemployment in a New-Keynesian Model", Documents de travail du Centre d'Economie de la Sorbonne, 15043.

WIJNBERGEN, S. V. (1985). “Oil Price Shocks, Unemployment, Investment and the Current Account: An Intertemporal Disequilibrium Analysis", The Review of Economic Studies, 52(4): 627-645.

YARDIMCIOĞLU, F. \& BEŞEL, F. (2013). "İşsizlik-Petrol Fiyatları İlişkisi: Yapısal Kırılmalar Altında Türkiye Örneği (1980-2012)”, Turkish Studies, 8(8): 2197-2211.

YAYLALI, M. \& LEBE, F. (2012). "İthal Ham Petrol Fiyatlarının Türkiye'deki Makroekonomik Aktiviteler Üzerindeki Etkisi”, Marmara Üniversitesi İ.İ.B.F. Dergisi, 32(1): 43-68.

YILANCI, V., ÖZGÜR, O., \& GÖRÜŞ, M. S. (2019). "The Asymmetric Effects of Foreign Direct Investment on Clean Energy Consumption in BRICS Countries: A Recently Introduced Hidden Cointegration Test", Journal of Cleaner Production, 237: 1-9.

YILANCI, V. \& ERİ̧, Z. A. (2013). "Purchasing Power Parity in African Countries: Further Evidence from Fourier Unit Root Tests Based on Linear and Nonlinear Models", South African Journal of Economics, 81(1): 20-34. 